
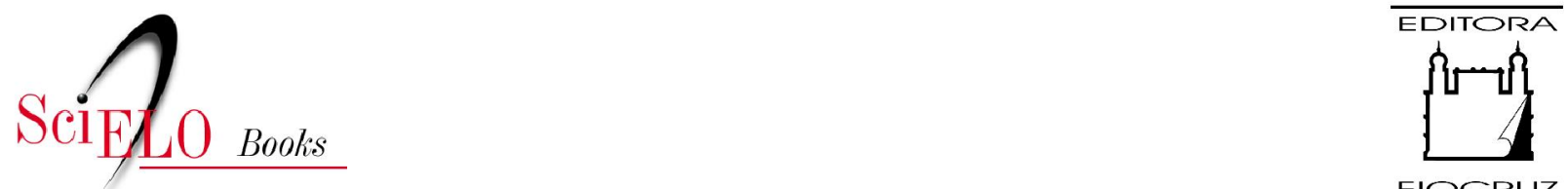

FIOCRUZ

\title{
Os processos e critérios de escolha de livros didáticos de português \\ o que dizem os professores?
}

\author{
Taíza Ferreira de Souza Cavalcanti \\ Alexsandro da Silva
}

\section{SciELO Books / SciELO Livros / SciELO Libros}

CAVALCANTI, T. F. S., and SILVA, A. Os processos e critérios de escolha de livros didáticos de português: o que dizem os professores? In: SOUZA, F. M., and ARANHA, S. D. G., orgs.

Interculturalidade, linguagens e formação de professores [online]. Campina Grande: EDUEPB, 2016, pp. 67-102. Ensino e aprendizagem collection, vol. 2. ISBN 978-85-7879-347-0. Available from: doi: 10.7476/9788578793470.0006. Also available in ePUB from:

http://books.scielo.org/id/qbsd6/epub/souza-9788578793470.epub.

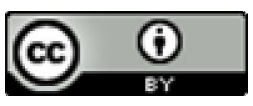

All the contents of this work, except where otherwise noted, is licensed under a Creative Commons Attribution 4.0 International license.

Todo o conteúdo deste trabalho, exceto quando houver ressalva, é publicado sob a licença Creative Commons Atribição 4.0.

Todo el contenido de esta obra, excepto donde se indique lo contrario, está bajo licencia de la licencia Creative Commons Reconocimento 4.0 . 


\title{
OS PROCESSOS E CRITÉRIOS DE ESCOLHA DE LIVROS DIDÁTICOS DE PORTUGUÊS: o que dizem os professores?
}

\author{
Taíza Ferreira de Souza Cavalcanti (UFPE) \\ Alexsandro da Silva (UFPE)
}

\begin{abstract}
"Quando a gente aprende a ler, as letras, nos livros, são grandes. Nas cartilhas - pelo menos nas cartilhas do meu tempo - as letras eram enormes" (VERÍSSIMO, 2008, p. 111).
\end{abstract}

Ao iniciar nossas considerações acerca do processo de escolha do livro didático de português vivenciado por professores de língua portuguesa atuantes no Ensino Fundamental, remetemo-nos ao fragmento da crônica de Luís Fernando Veríssimo (1998), porque, quando ele faz a menção às cartilhas do seu tempo, provoca-nos a refletir sobre os livros escolares de uma determinada época, na qual a escola não era acessível a todos e não existiam grandes editoras, nem políticas públicas para avaliação e distribuição de livros didáticos (LDs). 
Diferentemente dessa época, hoje podemos olhar para uma escola que, apesar de apresentar limitações políticas, estruturais e pedagógicas, expandiu o seu acesso aos estudantes de classes populares, assim como ampliou o acervo de materiais impressos nela disponíveis, entre os quais se incluem os livros didáticos. Esse recurso, outrora notadamente escasso nas salas de aula, permitiu contemplar a necessidade de alunos e professores no que se refere à existência de um material de apoio ao ensino e à aprendizagem.

Nesse contexto, com a criação do Programa Nacional do Livro Didático (PNLD), as questões relacionadas à escolha e ao uso de livros didáticos nas escolas públicas brasileiras passaram a receber novos encaminhamentos políticos e pedagógicos. Hoje, os professores têm mais autonomia para escolher o livro didático e os alunos da educação básica passaram a receber livros da maior parte das disciplinas das áreas do currículo escolar.

O PNLD, tendo em vista disponibilizar livros didáticos de melhor qualidade, se tornou um instrumento de suma importância para a melhoria do LDP ao definir critérios avaliativos que têm contribuído para a incorporação de novas orientações teóricas e metodológicas ao LDP. Desse modo, é necessário que esse recurso atenda, além de critérios gerais, critérios específicos da área, correspondentes a cada eixo do ensino de língua portuguesa, os quais se baseiam, em muitos aspectos, nas discussões teóricas fomentadas, principalmente, a partir da década de 80 do século passado. Em outras palavras, é critério de avaliação dos livros didáticos a adequação das propostas dos eixos de leitura, produção de textos escritos, oralidade e análise linguística. 
Nessa direção, concordamos com Rangel (2005), quando observa que,

O PNLD, especificamente a partir da avaliação, estabeleceu perspectivas teóricas e metodológicas bastantes definidas para o LDP, perspectivas estas que se tornaram possíveis graças a uma movimentação no campo de reflexão sobre o ensino da língua materna (RANGEL, 2005, p.14).

Sendo assim, a submissão dos livros a um processo de avaliação criterioso e sistemático passou a requerer que editoras buscassem adequar as suas produções aos padrões estabelecidos pelo Ministério da Educação (MEC) $\mathrm{e}$, consequentemente, produzissem livros que atendessem em certa medida às perspectivas teóricas mais atuais no campo do ensino de língua.

Atualmente, embora o professor disponha de variados recursos pedagógicos para subsidiar as suas práticas de ensino, o livro didático continua sendo um dos materiais mais frequentemente utilizados em sala de aula, provavelmente porque a coletânea textual, as propostas de atividades, as sugestões de projetos de didáticos e os demais recursos que o constituem podem facilitar o trabalho docente. Segundo Batista e Val (2004, p.17), “o livro didático está presente cotidianamente na sala de aula e constitui um dos elementos básicos da organização do trabalho docente".

Desse modo, reconhecendo a importância que o livro didático tem no cenário da educação brasileira, assim 
como o surgimento e desenvolvimento do PNLD, que avalia e distribui esses livros, o presente estudo buscou investigar como ocorre o processo de escolha do LDP e quais os critérios considerados pelos docentes ao realizarem suas escolhas.

\section{O PNLD e o processo de escolha dos livros didáticos}

A partir dos anos de 1970, o quantitativo de alunos nas escolas públicas brasileiras foi se expandindo, o que fez emergir a necessidade de novos direcionamentos políticos e pedagógicos para que a escola pudesse atendê-los. Tais encaminhamentos começaram a acontecer de forma mais efetiva com a chegada dos anos 1980, época na qual o governo iniciou a disponibilização de maiores investimentos financeiros para o campo educacional e que foi marcada pela ruptura com paradigmas pedagógicos até então cristalizados na história da educação.

Nesse contexto de mudanças, o Governo Federal, através do decreto Lei $n^{\circ} 91.542$ de 19 de agosto de 1985, estabeleceu, entre outras determinações, que os livros didáticos seriam escolhidos pelos professores, conforme a sua área de atuação, e deveriam ser utilizados por três anos até o momento da nova escolha. Esse decreto também estabeleceu o fim da participação financeira dos Estados no processo de aquisição e distribuição dos livros ${ }^{1}$.

Essas medidas criaram o Programa Nacional do Livro didático (PNLD), em parceria com o Fundo Nacional de Educação (FNDE), órgão federal responsável pela

1 Informações disponíveis no site do FNDE. 
administração de recursos que viabilizam a aquisição, avaliação e distribuição dos livros didáticos. Ao discorrer sobre a implementação desse Programa, Bagno (2007, p.18) argumenta que,

Desde sua primeira edição, o PNLD vem provocando uma transformação radical na cultura do livro didático em nosso país. Vencida a resistência inicial das grandes empresas editoriais, e também a de muitos autores - que se recusavam a incorporar naquelas obras uma nova filosofia de ensino-aprendizagem que substituísse a velha prática de transmissão mecânica de conteúdos tradicionais, sem apelo à participação ativa-criativa do aprendiz (e do docente) -, é possível dizer que o material didático hoje no mercado brasileiro apresenta inegáveis qualidades, sobretudo em comparação com o que se produzia antes (BAGNO, 2007, p.18).

Inicialmente, quando foi criado em 1985, o PNLD não apresentava a organização e atribuições que tem hoje, visto que esses aspectos foram modificados e ampliados a partir de 1996 (BATISTA; COSTA VAL, 2004). Devido às atribuições que caracterizam esse Programa, Costa Val (2009, p.13) define o PNLD como "parte das políticas públicas de educação desenvolvidas pelo MEC. Seu objetivo é a distribuição gratuita de livros didáticos para 
todos os alunos das escolas públicas do ensino fundamental (EF) no Brasil".

Essa política de avaliação e distribuição de livros didáticos não atingiu imediatamente todos os níveis de ensino, pois foi sendo gradativamente implantada, de modo que, inicialmente, atendia apenas aos estudantes do ensino fundamental. A partir de 2006, começou a disponibilizar livros didáticos para os estudantes do ensino médio, atendimento que se iniciou pelos livros de português e matemática e, gradualmente, foi se ampliando até abranger todas as disciplinas.

Desde a implantação do PNLD, muitas modificações relacionadas à presença dos LDs na escola aconteceram. Tais mudanças envolveram mercado editorial, investimento financeiro, adequação dos livros face aos novos paradigmas científicos e metodológicos, entre outras modificações, que, de forma gradativa, exigiram desse Programa uma organização sistemática e criteriosa de suas ações (BATISTA, 2004; BATISTA; COSTA VAL, 2004; COSTA VAL, 2009; BATISTA; ROJO, 2006).

Para tal organização, o PNLD tem-se desenvolvido por meio do cumprimento de algumas etapas, iniciadas pela adesão das redes ao Programa e contemplando ainda a inscrição das editoras, a avaliação das coleções, o processo de escolha realizada pelos professores e, por fim, o recebimento dos exemplares.

Ao analisarmos tais etapas, percebemos que o PNLD é realizado por meio de ações que buscam assegurar o direito de alunos e professores de escolas públicas a terem acesso a livros didáticos de melhor qualidade. Nessa direção, faz-se necessário que esses recursos constituam subsídios que estejam a serviço da prática docente, de forma 
que, ao abordarem os conteúdos, apresentem propostas de atividades diversificadas que ampliem o desenvolvimento dos processos de ensino e aprendizagem. Como aponta Pavão (2006, p.4), "o livro deve contribuir para que o professor organize sua prática e fornecer questões de aprofundamento das concepções pedagógicas desenvolvidas na escola".

Entretanto, apesar das ações desenvolvidas pelo PNLD, o processo de escolha do LD nem sempre tem acontecido da maneira prevista pelo Programa. Batista (2004), em pesquisa de caráter exploratório realizada com professores que participaram do processo de escolha no PNLD/2001, constatou que os docentes demonstraram possuir informações limitadas sobre o processo de avaliação dos livros didáticos. Nessa mesma direção, a investigação realizada por Costa Val (2002) apontou que os professores preferiam consultar os exemplares das coleções didáticas em vez do Guia. Quanto a esse material, os professores participantes desse estudo declararam que ele não havia chegado à escola a tempo suficiente para ser consultado, além de a quantidade de exemplares ser insuficiente para atender a todos os docentes. Em alguns casos, o Guia ficava sob o controle da equipe pedagógica da escola, o que também dificultava o contato dos professores com esse material e, consequentemente, com a avaliação nele presente sobre os livros.

No que alude ao momento da escolha do livro, Costa Val (2002) observou que cada caso apresentava suas peculiaridades, mas que, geralmente, o momento da escolha era organizado pelas secretarias municipais de educação, que convidava os professores para se reunirem por área de atuação. Nessa reunião, os docentes negociavam suas 
propostas de escolha, indicando os livros que preferiam e, em outros casos, eram realizadas plenárias com votações sobre qual livro deveria ser escolhido.

Nessa mesma linha de investigação, a pesquisa desenvolvida por Castanheira e Evangelista (2002), que teve como objetivo perceber padrões recorrentes ou diferenciados de processos de escolha dos LDs em escolas públicas do país, constatou situações diversificadas no que se refere à escolha, ao recebimento e ao uso dos livros de língua portuguesa e alfabetização. Uma das tendências sinalizadas na pesquisa aponta que, provavelmente, havia uma relação entre o processo de escolha e a organização escolar, uma vez que as escolas que demostraram maior organização pedagógica fizeram opção de escolha por livros mais qualificados.

A segunda tendência sinalizada na pesquisa apontou que, nos casos das escolas que se organizavam de forma híbrida (ciclos e séries), os padrões de escolha foram diferenciados, pois foi observado que, nas fases iniciais do ciclo, os professores demonstravam um padrão de preferência por livros que apresentam melhores recomendações, enquanto que nas séries finais do segmento observou-se preferência por livros menos qualificados. Ainda foi observado que, em alguns casos, os professores não utilizaram os livros recebidos, visto que, embora esses fossem bem avaliados, não correspondiam à escolha realizada, o que fazia com que utilizassem outros manuais.

Diante do exposto, reconhecendo que as práticas de ensino são muitas vezes subsidiadas pelo uso do livro didático, decidimos investigar como ocorreu o processo de escolha do LDP numa escola estadual de Pernambuco, 
situada na cidade de Arcoverde, e quais os critérios os docentes de língua portuguesa utilizaram para escolher as coleções didáticas.

\section{O estudo sobre os processos e critérios de escolha de livros didáticos: campo, participante e procedimentos}

Compreendendo que uma pesquisa nasce da necessidade de um conhecimento novo ou mais profundo sobre de uma questão que nos inquieta, realizamos esse estudo objetivando investigar como ocorreu o processo de escolha do LDP em uma escola da rede estadual de ensino de Pernambuco, situada no município de Arcoverde-PE, e quais foram os critérios considerados pelos docentes ao realizarem suas escolhas.

Para delimitarmos nosso campo de estudo, fizemos um estudo exploratório nas escolas pertencentes à Secretaria Estadual de Educação de Pernambuco, localizadas no município de Arcoverde-PE, com o objetivo de conhecer quais foram as coleções ou os livros didáticos de língua portuguesa adotadas pelas escolas e/ou professores no âmbito do PNLD/2014. Ao visitarmos essas instituições de ensino, constatamos que 3 (três) das 10 (dez) escolas visitadas fizeram a opção pela coleção "Projeto Teláris: Português", da Editora Ática, 2 (duas) escolheram a "Para Viver Juntos: Português", da Editora SM e outras 2 (duas) escolheram a coleção "Jornadas.port - língua portuguesa", da Editora Saraiva". As demais escolheram, cada uma, um livro diferente.

Mobilizados pelo objetivo mencionado anteriormente, e diante dos dados obtidos durante o estudo 
exploratório, realizamos uma sessão de grupo focal (GF), que nos permitiu ter acesso, por meio dos depoimentos dos docentes, a como se deu o processo de escolha do LDP e quais critérios de escolha foram utilizados pelos professores. Escolhemos essa técnica por compreendermos que ela possibilita ao pesquisador conhecer o que cada participante de um determinado grupo social pensa a respeito de um assunto comum, ou seja, conhecer o que um grupo pesquisado pensa sobre um tema que faz parte das suas práticas cotidianas (GATTI, 2012).

Para organização e realização da sessão do GF, visitamos as escolas nas quais as coleções de LDP adotadas na rede estadual de ensino de Arcoverde-PE foram as mais escolhidas, visando a convidar os professores de português a participarem da pesquisa, que seria realizada em cada escola, conforme horário a ser combinado com os professores. No entanto, devido a razões operacionais e/ ou de receptividade, não foi possível efetivar o estudo em todas elas. Por isso, participaram da referida sessão uma professora e dois professores de língua portuguesa de uma das escolas. No quadro a seguir, apresentamos o perfil desses professores. 
Quadro 1- Dados pessoais e profissionais dos(as) professores (as)

\begin{tabular}{|c|c|c|c|}
\hline $\begin{array}{l}\text { Dados dos } \\
\text { professores }\end{array}$ & Alice & Mário & Felipe \\
\hline Idade & 41 anos & 26 & 27 \\
\hline $\begin{array}{l}\text { Graduação } \\
\text { (curso, rede } \\
\text { e ano de } \\
\text { conclusão) }\end{array}$ & $\begin{array}{c}\text { Letras } \\
\text { Instituição } \\
\text { Pública } \\
1997\end{array}$ & $\begin{array}{l}\text { Letras } \\
\text { Instituição } \\
\text { Pública } \\
2010\end{array}$ & $\begin{array}{l}\text { Letras } \\
\text { Instituição } \\
\text { Pública } \\
2011\end{array}$ \\
\hline $\begin{array}{l}\text { Pós- } \\
\text { graduação } \\
\text { (latu sensu, } \\
\text { stricto sensu) }\end{array}$ & $\begin{array}{l}\text { Especialização } \\
\text { em Metodologia } \\
\text { do Ensino } \\
\text { de Língua } \\
\text { Portuguesa - } \\
\text { 2006/2007 }\end{array}$ & $\begin{array}{c}\text { Especialização } \\
\text { em Metodologia } \\
\text { do Ensino } \\
\text { de Língua } \\
\text { Portuguesa - } \\
\text { 2011/2012 }\end{array}$ & $\begin{array}{c}\text { Especialização } \\
\text { em Metodologia } \\
\text { do Ensino } \\
\text { de Língua } \\
\text { Portuguesa } \\
\text { 2012/2013 }\end{array}$ \\
\hline $\begin{array}{l}\text { Quantidade } \\
\text { de anos de } \\
\text { experiência } \\
\text { como } \\
\text { docente }\end{array}$ & $\begin{array}{c}9 \text { anos } \\
\text { (atua desde } \\
2006)\end{array}$ & $\begin{array}{c}5 \text { anos }^{2} \\
\text { (contratado } \\
\text { desde 2012) }\end{array}$ & $\begin{array}{c}2 \text { anos } \\
\text { (contratado } \\
\text { desde 2012) }\end{array}$ \\
\hline $\begin{array}{l}\text { Atuação em } \\
\text { outra escola } \\
\text { ou rede de } \\
\text { ensino }\end{array}$ & Sim & Não & Sim \\
\hline $\begin{array}{l}\text { Situação de } \\
\text { trabalho na } \\
\text { rede }\end{array}$ & Efetiva & Contratado & Contratado \\
\hline
\end{tabular}

Fonte: elaboração dos autores

Para analisar os dados gerados nesse estudo, utilizamos a técnica da análise de conteúdo (BARDIN, 2011), que nos possibilitou categorizar e descrever os dados obtidos

2 O professor Mário possuía três anos de experiência como estagiário e dois como professor contratado. 
e inferir informações. Nesse sentido, como objetivávamos interpretar os dados explícitos e, além desses, os conteúdos implícitos nos documentos construídos por meio da transcrição das falas dos professores envolvidos na pesquisa, seguimos as etapas sugeridas por Bardin (2011): a) pré-análise; b) exploração do material; c) tratamento dos dados, inferência e interpretação.

No entanto, esse método não constitui um procedimento rígido e fechado em si mesmo, mas um procedimento flexível, que permite ao pesquisador construir seus próprios caminhos de observação dos dados. Porém, tais caminhos são construídos de acordo com a organização das etapas mencionadas.

\section{Livros didáticos de Português: processos e critérios de escolha}

\section{O processo de escolha}

Um dado importante que emergiu em meio as interações entre os professores participantes do GF diz respeito à análise que eles fizeram dos volumes das coleções de LDP quando chegavam à escola. Essa análise ocorreu em dias que antecederam o momento da escolha e aconteceu, primeiro, de modo individual e, depois, coletivamente. Em outras palavras, cada docente, ao receber as coleções, analisava-as individualmente e, posteriormente, socializava com os demais as suas impressões e opiniões a respeito do material recebido. Essas socializações aconteceram durante os intervalos (recreio) ou ao final do dia. Porém, devido à incompatibilidade de horário dos professores, nem sempre era possível que todos se reunissem 
para discutirem qual coleção seria mais apropriada para ser escolhida. Tais impressões foram reconhecidas ao analisarmos os depoimentos concedidos pelos professores, conforme apontam os extratos a seguir:

Moderadora: Como aconteceu o processo de escolha do livro didático?

Professor Felipe: /.../ na verdade, cada professor analisou individualmente o livro, levou também pra casa, observou os textos, as propostas de atividades e depois o consenso.

Professora Alice: Veja só, como os dias dos professores nem sempre coincidem, então a gente sempre, nos momentos... “E aí, professor Mário, já analisou? "Não". Então vamos parar no final do dia pra gente ver direitinho. "E aí, você gostou mais de qual? Oh, eu tô gostando desses dois. E você?" Então, assim, havia sempre essa discussão nos intervalos. E assim... os que se encontravam já iam entrando num consenso, depois a gente ouviu a opinião de outros professores que não estavam naquele momento. Mas (...) o tempo foi se esvaindo. Não que a gente se sentiu forçado por conta do tempo, não. $O$ problema foi de encontro mesmo!(...). Então, assim, houve divergência em relação a Mário e tudo mais (informações verbais). 
Esses dados apontam que o processo de escolha do LD não aconteceu aleatoriamente, visto que os docentes buscaram "(re)criar" espaços, momentos ou mesmo possibilidades para analisar e discutir sobre o LDP a ser adotado. Entretanto, a fala da professora Alice parece revelar que, além de ter havido opiniões divergentes entre eles acerca das coleções de LDPs analisadas, o tempo para que pudessem se encontrar e discutir sobre o material recebido não foi satisfatório.

A reflexão sobre esses dados permite inferir que, apesar das limitações impostas pelo tempo e horários dos professores, questões essas inerentes aos fatores condicionantes de cada instituição escolar (TARDIF, 2008), os docentes demonstraram autonomia para decidir qual livro seria usado por eles em sala de aula. Isso fez com que a escolha desse recurso não fosse reduzida a uma resposta exigida pelas políticas educacionais, mas, sim, uma atividade que mobilizou os professores. Nessa ótica, concordamos com Menezes et al (2012, p.4) quando declaram que "a escolha do LD [...] deve ser, portanto, um exercício de autonomia pedagógica do professor, que, de acordo com seus próprios princípios, pode escolher e decidir um valioso apoio para sua prática".

Quanto à discordância de opiniões sobre a coleção que seria escolhida, o extrato a seguir ilustra essa discussão:

Mário: (...) Nos reunimos numa quarta-feira e nos sentamos e escolhemos, com apoio de uma coordenadora pedagógica que não faz mais a coordenação conosco, que é professora M. Ela fez a fala, pelo livro 
que nós adotamos, onde eu e uma outra profissional, professora ... é... Nós havíamos optado pelo Singular $\&$ Plural, que foi um dos livros, dos produtos abordados numa dessas formações e nós gostamos.

Felipe: É da Moderna esse [livro]?

Mário: Esse Singular \& Plural é da Moderna. Aí houve a escolha pela maior parte, né? Professor A, professor C...

Alice: A diferença foi só de um voto, né?

Mário: De um voto, para a coleção Viver Juntos. Para Viver Juntos, que é da editora $\mathrm{SM}$, que é vinculada à editora Moderna, mas na verdade não é editora Moderna (informações verbais).

A análise desses dados permite-nos perceber que a organização dessa reunião, com presença da coordenadora, não inibiu que houvesse divergência de opiniões entre os mestres. Essa discordância provavelmente iniciou-se devido aos desencontros de horários entre os docentes, o que pode ter dificultado o compartilhamento de informações e opiniões sobre as coleções, e prevaleceu mesmo durante a reunião dedicada à efetivação da escolha, na qual três professores optaram pela coleção "Para 
Viver Juntos", da editora SM, e dois professores preferiram a coleção "Singular \& Plural", da editora Moderna.

Para que pudéssemos obter uma visão geral dessas coleções, organizamos o quadro a seguir, a partir das resenhas das coleções apresentadas no Guia de Livros Didáticos:

Quadro 2- Visão geral das coleções didáticas que os (as) professores (as) indicaram para escolha

\begin{tabular}{|c|c|c|}
\hline $\begin{array}{l}\text { Eixos de } \\
\text { ensino }\end{array}$ & $\begin{array}{l}\text { Para Viver Juntos: } \\
\text { português }\end{array}$ & $\begin{array}{l}\text { Singular e Plural - } \\
\text { Leitura, Produção e } \\
\text { Estudos da Linguagem }\end{array}$ \\
\hline Leitura & $\begin{array}{l}\text { O trabalho é desenvolvido } \\
\text { "por meio de uma coletânea } \\
\text { textual que favorece } \\
\text { experiências significativas } \\
\text { para a formação do leitor" } \\
\text { (BRASIL, 2013, p.76) e } \\
\text { articula-se com as atividades } \\
\text { de produção escrita. }\end{array}$ & $\begin{array}{l}\text { Desenvolve o trabalho a } \\
\text { partir de vários gêneros } \\
\text { textuais, e "contempla } \\
\text { estratégias produtivas no } \\
\text { processo de formação de } \\
\text { leitores" (BRASIL, 2013, } \\
\text { p.105). }\end{array}$ \\
\hline $\begin{array}{l}\text { Produção } \\
\text { de textos } \\
\text { escritos }\end{array}$ & $\begin{array}{l}\text { As atividades de produção } \\
\text { valorizam "os usos sociais } \\
\text { dos gêneros e explicitam } \\
\text { seu contexto de produção" } \\
\text { (BRASIL, 2013, p.77). }\end{array}$ & $\begin{array}{c}\text { As atividades de } \\
\text { produção articulam-se } \\
\text { às atividades de leitura. } \\
\text { A coleção oferece } \\
\text { orientações para que as } \\
\text { atividades de produção } \\
\text { sejam realizadas. Essas } \\
\text { atividades consideram } \\
\text { os aspectos referentes à } \\
\text { "esfera, ao suporte, ao } \\
\text { gênero e ao destinatário" } \\
\text { (BRASIL, 2013, p.108). }\end{array}$ \\
\hline
\end{tabular}




\begin{tabular}{|c|c|c|}
\hline $\begin{array}{l}\text { Eixos de } \\
\text { ensino }\end{array}$ & $\begin{array}{c}\text { Para Viver Juntos: } \\
\text { português }\end{array}$ & $\begin{array}{l}\text { Singular e Plural - } \\
\text { Leitura, Produção e } \\
\text { Estudos da Linguagem }\end{array}$ \\
\hline Oralidade & $\begin{array}{l}\text { Assim como os demais } \\
\text { eixos, também enfatiza o } \\
\text { trabalho sobre os gêneros } \\
\text { textuais. Para tanto, são } \\
\text { apresentadas ao aluno } \\
\text { estratégias e procedimentos } \\
\text { para a produção do discurso } \\
\text { oral, que favorecem o } \\
\text { desenvolvimento das } \\
\text { “habilidades linguísticas } \\
\text { dos alunos” (BRASIL, 2013, } \\
\text { p.74). }\end{array}$ & $\begin{array}{l}\text { Valoriza o trabalho com } \\
\text { os diversos gêneros } \\
\text { textuais e articula-se com } \\
\text { as atividades de leitura } \\
\text { e escrita. De acordo com } \\
\text { o GDL a "oralidade é } \\
\text { intensamente explorada } \\
\text { desde a abertura das } \\
\text { unidades, em atividades } \\
\text { que envolvem interação } \\
\text { em sala de aula" } \\
\text { (BRASIL, 2013, p.108). }\end{array}$ \\
\hline $\begin{array}{l}\text { Análise } \\
\text { Linguística }\end{array}$ & $\begin{array}{l}\text { A perspectiva predominante } \\
\text { é a textual discursiva, } \\
\text { apesar de haver } \\
\text { algumas recorrências de } \\
\text { metalinguagem. De forma } \\
\text { geral, favorece a análise e } \\
\text { reflexão sobre o uso dos } \\
\text { recursos linguísticos nos } \\
\text { diversos contextos de leitura } \\
\text { e produção. }\end{array}$ & $\begin{array}{c}\text { O tratamento desse eixo } \\
\text { de ensino ocorre em um } \\
\text { caderno exclusivo, mas } \\
\text { também é retomado } \\
\text { em algumas atividades } \\
\text { de outros cadernos. } \\
\text { Segundo o Guia os LDs } \\
\text { dessa coleção favorecem } \\
\text { a análise e reflexão sobre } \\
\text { a língua, entretanto, } \\
\text { no segundo caderno } \\
\text { onde é tratado esse eixo } \\
\text { de ensino, predomina } \\
\text { uma perspectiva } \\
\text { metalinguística } \\
\text { (classificações e } \\
\text { nomenclaturas). Sobre } \\
\text { esse aspecto o aponta que } \\
\text { Guia “A apresentação } \\
\text { desse eixo em um } \\
\text { caderno específico pode } \\
\text { dificultar sua articulação } \\
\text { com os demais” (BRASIL, } \\
\text { 2013, p.105). }\end{array}$ \\
\hline
\end{tabular}

Fonte: elaboração dos autores. 
Conforme as informações expostas no quadro, observamos que as coleções que dividiram as opiniões dos docentes participantes no processo de escolha pareciam valorizar o trabalho com os gêneros textuais/discursivos e tentar promover atividades de análise e reflexão sobre a língua, embora haja recorrências de atividades de classificação e identificação de palavras. Entretanto, na coleção "Singular e Plural- Leitura, Produção e Estudos da Linguagem", essas ocorrências parecem ser mais evidentes, uma vez que o Guia aponta que a perspectiva adotada é predominantemente transmissiva, além de o tratamento das atividades de gramática/análise linguística ocorrer em um caderno à parte não facilitar a articulação com os demais eixos de ensino. Desse modo, pressupomos que a preferência dos docentes por essas coleções pode se relacionar ao modo como cada um deles compreende o ensino da língua portuguesa.

Nesse aspecto, esses dados assemelham-se com os resultados obtidos na pesquisa realizada por Lerner (2004), na qual constatou que os professores selecionam LDPs cujo modo de tratar os conteúdos identifica-se com suas concepções teórico-práticas sobre o ensino. Sobre essa perspectiva, a pesquisadora constatou que "os professores escolhem livros que garantem certa segurança, porque confirmam seu saber-fazer" (p.117). Isso pode justificar o fato de um professor gostar do LDP que foi adotado pela escola, enquanto outro docente, da mesma instituição, expressar verdadeira aversão a esse recurso didático, uma vez que não concorda com as propostas de atividades que ele apresenta, conforme parece ter sido o caso dos professores que aqui investigamos. 
A ausência do Guia no processo de escolha e a participação das editoras

Ao conversarmos com os professores sobre como aconteceu a escolha do LDP, observamos que os mestres não mencionaram se haviam consultado o Guia de Livros Didáticos do PNLD antes ou durante a reunião destinada à escolha. Diante disso, fizemos a seguinte indagação:

Moderadora: Vocês consultaram o Guia que o MEC encaminha para a escola com a avaliação?

Professora Alice: Não.

Moderadora: Mas o Guia mesmo, vocês não viram? Veio para a mão de vocês?

Professora Alice: Não.

Professor Mário: Não chegou.

Professor Felipe: Não. Na verdade a gente só analisou em relação também só ao currículo, só isso, mas em relação ao guia não.

Professora Alice: Apesar de todo cuidado com a escolha do livro, ainda tá deixando a desejar. Apesar de toda preocupação, tanto das editoras, quanto dos professores, quanto da parte pedagógica da escola, dos orientadores e tudo mais, ainda há falhas, 
não é? A gente vê nesse sentido de um acordo único pra estudar aquilo ali, pra ver os prós e contras, pra pegar esse guia, e essa preocupação de ir à internet e ver as opiniões de outros, de mestres ou de outros colegas de mesma área (informações verbais).

Tais dados evidenciam que o Guia do Livro Didático foi um elemento ausente no processo de escolha do LD nessa escola, pois os professores não o consultaram nem antes, nem durante a escolha. Segundo eles, suas decisões foram fundamentadas na análise das próprias das coleções e nas Orientações Teórico-Metodológicas (OTMs), as quais constituem um documento curricular da Secretaria Estadual de Educação - PE com indicação de conteúdos de ensino por componente curricular e ano de ensino.

Sobre esse aspecto, salientamos que os depoimentos dos docentes não revelaram indícios de que a escola teria recebido ou não o Guia, porém esclarecem que, na ausência dele, outros suportes e/ou agentes estiveram presentes, como, por exemplo, a consulta às OTMs e, conforme será observado mais adiante, a participação das editoras.

Tais dados remetem aos resultados das já citadas pesquisas desenvolvidas por Costa Val (2002) e Batista (2004), as quais constaram que a maioria dos professores investigados preferiu consultar as coleções de LDs recebidas, em vez de recorrer ao Guia de Livros Didáticos para nortear suas escolhas. Essa realidade também emergiu entre os dados obtidos na pesquisa de Oliveira (2013), que teve como objetivo descrever, analisar e compreender como professoras de $6^{\circ}$ e $9^{\circ}$ ano do ensino fundamental 
apropriaram-se dos livros didáticos da coleção "Tudo é Linguagem", adotada no triênio 2008- 2010, em uma escola estadual de Belém - PA. Nesse estudo, a pesquisadora mencionada observou que as professoras não consultaram o Guia no momento da escolha e fundamentaram sua opção pelo LDP nas consultas às coleções que foram encaminhadas pelas editoras.

Se compararmos os resultados apresentados pelas pesquisas de Costa Val (2002); Batista (2004); Oliveira (2013) com os dados de nosso estudo, considerando o distanciamento e/ou a aproximação temporal entre elas, observaremos que, apesar da gradativa expansão do PNLD nas duas últimas décadas, ainda há professores de língua portuguesa atuantes em escolas brasileiras que não consultam o Guia do LD. Essa consulta parece não estar ocorrendo seja porque esse catálogo não chega às escolas em tempo hábil, seja porque, quando chega, fica guardado e não é entregue aos professores ou, ainda, porque os mestres parecem desconhecer o fato de que esse material pode ser consultado na internet ou preferem mesmo não o utilizar.

Contrapondo-se à ausência do Guia, a análise dos dados apontou que a participação de algumas editoras no processo de escolha do LD foi intensa, uma vez que elas tanto encaminharam representantes para visitarem as escolas com a finalidade de divulgar as coleções didáticas, quanto ofereceram "formações" para os docentes. Eis os extratos que apontaram esses dados:

Professor Mário: É ... nós recebemos a visita do representante da editora em um momento pontual da nossa rotina.

$\mathrm{O}$ representante ou a representante, 
porque foram mais de duas editoras. Eles marcavam encontros pontuais em que nós podíamos analisar o material e, quando nós analisávamos o material, nós fazíamos anotações em papeis pra comparar o que esse livro tinha que aquele não tinha e confrontávamos com as OTMs para aquela série. Então isso ocorreu do sexto ao nono ano com o professor C, professora A, professora $\mathrm{D}$ e professora E, que não está presente agora.

Professora Alice: Complementando aí ... a representante, ela ... ela mostrava ... o que determinado ... vamos dizer ... produto oferecido por ela ... Existiu todo aquele trabalho, né? De apresentação mesmo. E ela dizia ... ela mostrava a atualização, se o livro foi modificado, se a edição renovada agora trouxe alguma coisa a mais. Então isso tudo pesa também! A apresentação da representante em si também é levada em consideração, tipo é ... o tempo dispensado pra determinada reunião, a organização, o que nos ofereceu. Então há representantes que não oferecem. Houve uma representante de uma das editoras que inclusive deu uma formação diferenciada em outro local para os professores da área. 
Professor Mário: Teve um outro formador de uma outra editora que nos convidou para fazer a formação num local específico da cidade, num hotel, e ... essa formação ela trazia ... ela fazia uma via de mão dupla: ela tanto mostrava um produto ofertado e quais os diferenciais desse produto, quanto nos trazia uma formação em língua portuguesa, mostrando em que aspectos aquele produto nos serviria. Então foram duas formações. [...] Quem foi dos nossos profissionais de português pra formação que houve no hotel que era a editora Saraiva que estava fazendo essa formação. A primeira que eu já falei foi a editora Moderna, com o tema gênero textual, gêneros textuais, e a editora Saraiva trabalhou muito os gêneros textuais nos instrumentos didáticos. Então ela colocou numa apresentação no data show com os eixos do MEC. Quem foi viu, mas ela pincelou (informações verbais).

Nesse contexto, percebemos que as editoras participaram do processo de escolha do LDP, por meio de reuniões organizadas pelos seus representantes para apresentar as coleções didáticas aos professores. Nessas ocasiões, esses representantes faziam exposições sobre as inovações ou mudanças que os LDPs apresentavam, o que demonstra 
uma tentativa, por parte das editoras, de persuadir os mestres a escolherem a coleção em questão.

Outro aspecto que merece ser observado nos depoimentos expostos anteriormente é que os mestres aproveitavam esses encontros com os representantes das editoras para se reunirem e observarem se a coleção didática que estava sendo oferecida contemplava os conteúdos curriculares propostos pelas OTMs. Sendo assim, essas reuniões pareciam constituir, para os docentes, mais uma oportunidade para análise e discussão sobre as coleções de LDP, uma vez que o tempo destinado exclusivamente para essas finalidades era limitado.

Além disso, as falas dos professores apontaram que a divulgação das coleções de LDPs não foi restrita a essas reuniões, uma vez que algumas editoras, sob a pretexto de divulgar as coleções didáticas, promoveram outros encontros com os docentes em ambientes externos às escolas para influenciar os professores na escolha. Além disso, a análise dos depoimentos dos colaboradores da pesquisa parece revelar que os mestres caracterizaram esses eventos como de divulgação dos LDs, mas também como momentos de formação continuada, pois algumas editoras contrataram, como uma estratégia adicional, especialistas para oferecerem cursos, que abordavam alguns conteúdos curriculares do ensino de língua portuguesa, à medida que apresentavam os LDPs.

Esses dados remetem à pesquisa desenvolvida por Costa Val (2002), na qual se constatou que a participação das editoras era acentuada no processo de escolha dos livros, pois, quando elas não se faziam presentes por meio da visita dos representantes, suas presenças eram materializadas por meio dos catálogos, cartazes e cursos 
que divulgavam as coleções. Ao fazer esse trabalho, essas empresas exerciam, consequentemente, maior influência que o Guia no momento da escolha.

\section{Os critérios considerados no momento da escolha da coleção de LDPS}

\section{Adequação do LDP às OTMs}

A análise dos dados evidenciou que um dos critérios utilizados pelos professores para escolher as coleções didáticas parece ter sido a adequação da coleção às OTMs. Como já dissemos anteriormente, no processo de escolha, os docentes observavam se as coleções didáticas que haviam recebido para análise contemplavam os conteúdos e indicadores de desempenhos propostos pelas OTMs. Eis as falas dos docentes que nos permitiram fazer essa interpretação:

Moderadora: Qual foi o critério, o principal critério que vocês utilizaram pra dizer: É esse livro aqui, não é esse. O que mais chamou a atenção de vocês nos livros ao optar por aquela coleção?

Professor Felipe: Na verdade, a gente só analisou em relação também só ao currículo, só isso, mas em relação ao guia não. 
Professor Mário: Eu acho que vai ser sucinta a nossa fala, assim rápida, e vai ser comum. A OTM, nós recebemos o parâmetro, num é Alice? Num é Felipe? E os livros que os colegas escolheram, que foi uma boa escolha também. Isso é assim ... Como eu vou dizer... Isso é, independentemente de minha escolha ter sido outra, foi uma boa escolha. Nós utilizamos, os meninos [os professores] utilizaram a questão de pegar a OTM pra ver o que era preciso. Eu lembro quando a professora Alice, na quarta-feira, pegou e [disse]: "Olha, esse aqui num tá de acordo, em comum acordo com esse livro. Esse aqui tá em comum acordo com esse livro". Porque a série que ela trabalha era justamente o oitavo ano, nono ano. Mário também: "Olhe, tá em comum acordo isso e isso". E é esse o padrão e eu creio, nós cremos em uníssimo que o padrão que se adequa, coordenadora, é esse [simulou como ocorreu a indicação do LDP a coordenadora]. E foi feito a escolha assim (informações verbais).

Ao analisarmos tais depoimentos, notamos que os professores, ao escolherem o LDP, preocuparam-se em observar a coleção na qual os conteúdos abordados mais se aproximavam dos conteúdos indicados pelas OTMs 
para serem ensinados em cada ano de ensino. Esses dados parecem revelar que, enquanto a consulta ao Guia foi uma ação ausente no processo de escolha dos LDPs nessa escola, a consulta às OTMs foi uma das ações que influenciaram diretamente os docentes a optarem pela coleção "Para Viver Juntos: Português", opção essa que não foi a de todos, mas que prevaleceu por ter sido definida pela maioria dos docentes.

Nesse sentido, pressupomos que essa influência das OTMs sobre a escolha do LDP deu-se em decorrência do monitoramento dos conteúdos trabalhados em cada bimestre do ano letivo, o qual é realizado ao final de cada unidade, por meio do Sistema de Monitoramento de Conteúdos (SMC) da Secretaria de Educação do Estado de Pernambuco.

A partir desse pressuposto, inferimos que havia certa preocupação, por parte dos professores, em desenvolver um trabalho em torno dos conteúdos estabelecidos pelas OTMs. Essa preocupação também foi constatada na pesquisa desenvolvida por Cavalcanti; Silva e Suassuna (2014), que perceberam o caso de duas professoras que buscavam trabalhar os conteúdos propostos pelas OTMs em virtude do monitoramento de conteúdos que era realizado.

Entretanto, não podemos afirmar que o livro escolhido contemple todos os conteúdos sugeridos pelas OTMs ou mesmo que os professores seguem à risca as recomendações constantes nesse documento, pois compreendemos que as situações vivenciadas no interior da sala de aula nem sempre refletem o que é estabelecido pelos programas de ensino. Apoiando-nos em autores como Chartier (2007); Duran (2008) e Ferreira (2007), compreendemos 
que há certa distância entre as determinações pedagógicas e o que realmente é vivenciado no interior da sala de aula.

\section{Adequação do LDP à realidade dos estudantes}

Outro critério utilizado pelos professores para definir a coleção didática a ser adotada foi a adequação dela à realidade dos estudantes. Para tanto, os professores, ao analisarem as coleções de LDPs, também atentaram para observar, além dos aspectos já abordados, algumas características presentes nas coleções, como, por exemplo, o material textual disponibilizado, as imagens, a atualização, entre outros aspectos que foram mencionados pelos docentes, os quais podem ser percebidos nos depoimentos a seguir:

Professora Alice: Particularmente, existe em mim uma preocupação nesse sentido de... de tornar o livro didático mais próximo possível do mundo em que nosso alunado se encontra hoje. As ilustrações, os textos, a relação... a contextualização, num é? Da gramática, o trabalho mesmo carinhoso. Até a ilustração eu levo em consideração. É... o... os anexos, as sugestões, o anote, é... sugestões de filmes, sugestões de outras leituras. Eu levo em consideração isso. [...] . 
Professor Felipe: É até porque assim, Alice, o nosso público, o publico da nossa escola ele é muito assim...: "Professor, e aí? O que que vai ter hoje? Ô, num tô afim de copiar no livro não" [exemplificando a fala do aluno]. Mas o livro tem que ter realmente uma... uma coisa que chame a atenção (informações verbais).

Diante dessas falas, notamos que, no momento de análise e escolha do LDP, os professores preocuparam-se em observar tanto o modo como as coleções didáticas tratavam os conteúdos, quanto as sugestões de leitura e filmes e imagens disponibilizadas. Além disso, observaram se os LDPs apresentavam atualizações e abordavam temas que se aproximavam do repertório cultual em que os alunas/ os estavam inseridos.

Desse modo, percebemos que a consideração desses itens constituiu mais um critério no qual os professores se apoiaram para escolher o LDP "Para Viver Juntos". Esse critério também foi reconhecido no estudo exploratório desenvolvido por Costa Val et. al. (2004), que investigaram os processos de escolha de LDs de alfabetização e língua portuguesa de ( $1^{\mathrm{a}}$ a $4^{\mathrm{a}}$ séries) por professores de escolas brasileiras. Ao objetivar compreender os padrões e os condicionantes dessas escolhas, constataram que a adequação do LDP aos estudantes que irão utilizá-los é um dos fatores decisivos no momento da escolha. Entretanto, o referido estudo destaca que é necessário analisar se esse critério, na realidade, não mascara outro fator: a subestimação da capacidade linguística e cognitiva dos estudantes. 
Ao relacionarmos os dados produzidos no estudo de Costa Val et. al. (2004) e os produzidos na realização dessa sessão de grupo focal, compreendemos que, apesar do marco temporal que separa as duas pesquisas, e, independentemente do nível de ensino em que o professor atua, o modo como as/os alunas/os se relacionariam com o LDP parece ser um dos fatores determinantes no momento da escolha.

\section{Relação do professor com o LDP}

Os professores, ao realizarem a escolha do LDP, pareciam buscar também identificar qual coleção didática poderia melhor facilitar a organização do seu trabalho na dinâmica do cotidiano da sala de aula, bem como subsidiar a gestão das diversas atividades com as quais se deparam diariamente. Eis um dos fragmentos que permitiu realizar essa análise:

Professora Alice: Assim, porque o professor Ele ... ele tá limitado também ao tempo, num é? O nosso tempo é muito corrido. Então, quando a gente vê o livro como um instrumento riquíssimo, então quanto mais ... Vamos dizer ... quanto mais rica, quanto mais é ... quanto mais facilitador, vamos dizer assim, do nosso dia-a-dia, para com nosso trabalho mesmo literário, é ... gramatical, linguístico. $\mathrm{O}$... o livro que nos oferecer essa ferramenta, vamos dizer assim, 
facilitando a compreensão, facilitando essa comunicação, trazendo esse atrativo no sentido de linguagem, de menos formalidade, vamos dizer assim, é esse livro que assim ... que a gente se apaixona (informações verbais).

Diante da declaração, percebemos que, para a professora Alice, o LDP necessita constituir-se como um material que colabore para organização do tempo pedagógico em sala de aula, de modo que a sua utilização possa facilitar o trabalho docente ao abordar os objetos de ensino de língua portuguesa.

Esses dados parecem revelar que o professor, ao adotar um LDP, espera que esse recurso apresente elementos que ofereçam múltiplas possibilidades de atuação do docente no que se refere aos objetos de ensino, por meio de uma linguagem acessível, que favoreça a comunicação entre aluno e professor e entre os estudantes e os conteúdos curriculares, como também apresente elementos que despertem o interesse dos alunos.

Quanto às contribuições proporcionadas pelo LDP ao trabalho do professor por meio das sequências de atividades sugeridas, Lerner (2004) destaca três pontos a serem observados. O primeiro relaciona-se à importância do LDP auxiliar o professor a conduzir a aula, oferecendo um conjunto de atividades que os alunos possam solucionar de forma mais independente, o que contribuirá para que o docente tenha mais tempo para atender aqueles que necessitam receber mais assistência. $\mathrm{O}$ segundo refere-se à necessidade de o LDP colaborar com a organização 
do tempo do professor no que se refere ao planejamento das atividades. O terceiro, por sua vez, vincula-se ao LD como fonte de informações acerca dos conhecimentos a serem estudados na sala de aula, de maneira que, além de favorecer a didatização desses conhecimentos, permita uma aproximação pessoal entre o aluno e os conteúdos estudados.

Pelo exposto, compreendemos que, tanto para a referida autora, quanto para a professora Alice, o LDP não se constitui como uma ferramenta didática que engessa as práticas de ensino, mas, sim, como um recurso que pode colaborar para a organização dessas práticas, possibilitando ao professor intervir do modo mais adequado ante a diversidade de situações que podem ser vivenciadas na sala de aula.

Nesse sentido, pressupomos que os docentes não constroem com o LDP uma relação de subserviência, mas, sim, de autonomia, uma vez que seus saberes possibilitam escolher se utilizarão ou não o LD e como o usarão, o que dependerá tanto da realidade de sala de aula, quanto dos elementos apresentados pelo LD.

\section{Considerações finais}

Os resultados do estudo que desenvolvemos evidenciaram que, apesar da autonomia exercida pelo docente ao escolher os LDPs, o processo de escolha parecia ocorrer de forma de não planejada, uma vez que os professores não dispunham de tempo e espaços apropriados para analisar e discutir sobre as coleções didáticas. Além disso, a atuação das editoras esteve presente nesse processo de 
escolha, enquanto o acesso ao Guia de Livros Didáticos pareceu restrito ou inexistente.

Quanto aos critérios utilizados para escolher o LDP, percebemos que os professores, valorizavam, principalmente, a adequação do material ao documento que regulava os conteúdos curriculares na rede ensino (as OTMs) e a sua pertinência (ilustrações, material textual, conteúdos, etc.) ao grupo de alunos com o qual atuavam. Além disso, os professores também pareciam selecionar livros que facilitassem a organização de seu trabalho pedagógico em sala de aula.

Com base na discussão apresentada, acreditamos que é necessário desenvolver ações que orientem as escolas a organizar melhor o processo de escolha do LDP, de forma que os gestores e coordenadores promovam encontros mais sistemáticos para que os professores possam dialogar melhor sobre a escolha do LD. Nessas situações, além de analisar as coleções, eles podem tomar conhecimento sobre as informações relativas ao Guia, inclusive a de que ele é disponibilizado para acesso na internet. Sobre esse aspecto, é importante salientar, porém, que a consulta ao Guia não invalida a análise das próprias coleções didáticas pelos professores, a quem cabe decidir sobre a adequação ou não do livro.

Sendo assim, concordamos com as palavras de Rojo (2006, p.51), quando observa que "o momento da escolha do livro faz parte de um cenário de arrumação da sala de aula e da escola para receber seus protagonistas mais importantes: seus alunos". Desse modo, acreditamos ser necessário que os docentes escolham um LDP que ofereça melhores condições de ensino e aprendizagem aos estudantes, o que requer que o momento da escolha seja 
organizado com tempo suficiente para que os mestres discutam sobre o livro a ser adotado, estabeleçam critérios para realizar a escolha, como também tenham acesso ao Guia e demais informações sobre o PNLD.

\section{REFERÊNCIAS}

ALBUQUERQUE, E. B. C. de; COUTINHO, M. L. Atividades de leitura nos livros didáticos de língua portuguesa. In: BARBOSA, M. L. F. de F.; SOUZA, I. P. de. (Orgs) Práticas de leitura e escrita no ensino fundamental. Belo Horizonte: Autêntica, 2006.

BARDIN, L. Análise do conteúdo. São Paulo: Edições 70, 2011.

BATISTA, A. A. G. O processo de escolha de livros: o que dizem os professores. In: BATISTA, A. A. G.; VAL, M. G. C. (Orgs) Livros de alfabetização e língua portuguesa: os professores e suas escolhas. Belo Horizonte: Ceale: Autêntica, 2004.

BATISTA, A. A. G.; COSTA VAL, Maria das G. Livros didáticos, controle do currículo, professores: uma introdução. In: BATISTA, A.A.G; VAL, M. G. C. Livros de alfabetização e de português: os professores e suas escolhas. Belo Horizonte: Ceale: Autêntica, 2004.

CASTANHEIRA, M. L. et. al. Processos de escolha, recebimento e uso de livros didáticos nas escolas públicas do país. Anais da 25 a Reunião Anual da ANPEd. Caxambu: ANPEd, 2002. 
CHARTIER, A. M. Práticas de leitura e escrita: história e atualidade. Belo Horizonte: Ceale/ Autêntica, 2007.

COSTA VAL, M. G. Os processos e critérios subjacentes a escolha do livro didático nas escolas públicas do País. In: Anais da 25 a Reunião Anual da ANPEd. Caxambu: ANPEd, 2002.

COSTA VAL, M. G. et. al. Padrões de escolha de livros didáticos e seus condicionantes: um estudo exploratório. In: BATISTA, A. A. G.; VAL, M. G. C. (Orgs) Livros de alfabetização e língua portuguesa: os professores e suas escolhas. Belo Horizonte: Ceale: Autêntica, 2004.

COSTA VAL, M. G. Sobre o PNLD. In: COSTA VAL, M. G. Alfabetização e língua portuguesa: livros didáticos e práticas pedagógicas. Belo Horizonte: Autêntica: Ceale/ FaE/UFMG, 2009. (Coleção Linguagem e Educação).

DURAN, M. C. G. Ensaio sobre a contribuição de Michel de Certeau à pesquisa em formação de professores e o trabalho docente. Educação \& Linguagem, ano 10, n.15, p.117-137, jan/jun, 2007.

FERREIRA, A. T. B. O cotidiano da escola como ambiente de fabricação de táticas. In: FERREIRA, S. T. B;. ALBUQUERQUE, E. B. C. de.; LEAl, T. F. (orgs) Formação continuada professores: questões para reflexão. 2 reimp. Belo Horizonte: Autêntica, 2007.

GATTI, B. A. Grupo focal na pesquisa em ciências sociais e humanas. Brasília: Liber Livro, 2012. (Série Pesquisa). 
LERNER, D. O. Livro didático e a transformação do ensino da língua. In: BATISTA, A.A.G.; VAL, M. G. C. Livros de alfabetização e de português: os professores e suas escolhas. Belo Horizonte: Ceale: Autêntica, 2004.

MENEZES, E. A. de O. O Livro didático como política educacional e o processo da sua escolha: uma experiência em municípios cearenses. In: XVI ENDIPE - Encontro Nacional de Didática e Práticas de Ensino.Campinas: UNICAMP, 2012. Disponível em: <http://www.infoteca. inf.br/endipe/smarty/templates/arquivos_template/ upload_arquivos/acervo/docs/2169p.pdf.> Acesso em: 20 mar. 2014.

OLIVEIRA, M. A. A. O ensino de língua portuguesa: usos do livro didático, objetos de ensino e gestos profissionais. 2013. Tese (Tese de Doutorado) - Universidade Estadual de Campinas. Departamento de Linguística Aplicada no Instituto de Ciências da Linguagem. Campinas, 2013.

PAVÃO, A. C. Proposta pedagógica. O Livro didático em questão. 2006. Disponível em:< http: // www. ufpe.br/ ceel>. Acesso em: 30 dez. 2013.

ROJO, R. O livro didático de língua portuguesa. In: O livro didático em questão. 2006. Disponível em:< http: / / www. ufpe.br/ceel>1. Acesso em: 30 dez. 2013. 